\title{
Spatial Day Light Autonomy and Energy Analysis of a Residential Building for Different Climatic Conditions and Window-to-Wall Ratios
}

\author{
Dr. R. Vijay Kumar ${ }^{1}$, Sandeep Kumar $\mathrm{N}^{2}$, Narsimha $\mathrm{K}^{3}$, Shiva Ram Reddy $\mathrm{K}^{4}$, Vamsee Krishna $\mathrm{E}^{5}$ \\ ${ }^{1}$ Associate Professor, Department of Civil Engineering, B V Raju Institute of Technology, Narsapur, India \\ 2 Junior Research Fellow, B V Raju Institute of Technology, Narsapur, India \\ ${ }^{3}$ UG Student Department of Civil Engineering, B V Raju Institute of Technology, Narsapur, India \\ ${ }^{4}$ UG Student, Department of Civil Engineering, B V Raju Institute of Technology, Narsapur, India \\ ${ }^{5}$ UG Student, Department of Civil Engineering, B V Raju Institute of Technology, Narsapur, India
}

\begin{abstract}
Building envelope of the structures plays a crucial role in the energy consumption. To decrease the amount of Energy Consumption in Building, Energy saving materials and Optimal sizing of Openings to be selected. In this aspect a model is simulated by using the Design Builder Software to Analyse the Spatial Daylight Autonomy, Thermal Comfort and Annual Energy Consumption. Windows impact the heat exchanges between indoor environment and outdoor environment. This possibly permit a proper utilization of solar energy. The research aims to investigate the influence of window-to-wall ratio in different of different climate conditions in India which has been introduced as hot dry, hot humid and moderate climates. The research has studied the most possible window-to-wall ration in the region based on previous work $5 \%, 10 \%, 15 \%$ and $20 \%$ out of the faced surface area of the building. This paper sketch out the modus operandi and the alike results of an analysis which targets to find out the ideal size of the glazed surface, which permits the minimum amount of overall energy consumption and determining the efficient building materials .The analyses and simulation procedures were performed using Design Builder software and the window dimensions are calculated in terms of the ratio between the glazed surface to the gross facade area, defined as window to wall ratio (WWR).
\end{abstract}

\section{INTRODUCTION}

Buildings constitute the sizeable energy- consuming sector in the economy, with over $33 \%$ of all final energy and $50 \%$ of overall electricity preoccupied there. Consequently, they are also accountable for roughly $33.33 \%$ of the total carbon emissions globally. The amount of the indoor environment need thermal comfort because of its impact on well-being, the activity of people, and energy requirements. For the thermal sensation of people, mean radiant temperature is one of the crucial variables. In order to study the energy behaviour of buildings, Thermal and energy simulation procedures are used by academics for evaluating building performance.

For residential building in various climates, thermal comfort can be done through simulations for losing or gaining heat. Design builder is one of the most helpful options for energy simulation generation with standards.

The overall annual energy consumption of a building depends on the building envelope. Doors and windows, as the main openings on building envelope, are weak in heat preservation and insulation of the building. Through the two components, the thermal energy can easily flow out of the building through radiation, convection, conduction phenomenon and air leakage. Thus, doors and windows have a direct effect on the energy efficiency of the building and the quality of indoor thermal environment. The typical envelope of buildings contains of door(s), windows, walls, roof and floor. The doors and windows consume 3 times more energy than the walls, 4 times more energy than the roofs and over 19 times more energy than the floor.

Besides the window-to-wall ratio and the components of building envelope, building materials like wall materials, plastering materials and insulation materials also influence the energy aspects of the building. Therefore, considering the various building materials and the efficient building material was determined with the simulation procedure was carried out with different combinations of building materials and window- to- wall ratios.

Hence, it is essential to explore how building energy consumption is factored by the various parameters of

* Corresponding author: vijaykumar.r@bvrit.ac.in 
windows. such as, orientation, window-to-wall ratio (WWR), heat transfer coefficient, shading coefficient, different building materials, wall materials, plastering materials and insulation materials under the circumastances of the local climate zone.

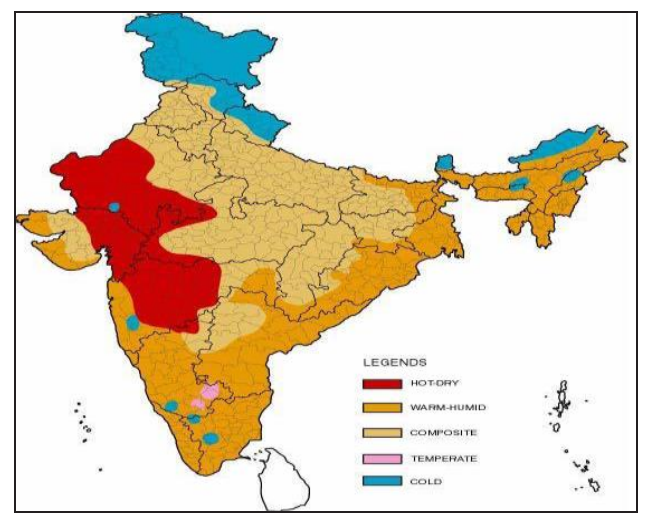

Fig.1 Climate Zone Map of India

The climatic zones considered are hot-dry, warmhumid, composite, temperate and cold. The main objective of considering the different climatic zones was to analyse the effect of temperature and climatic conditions on energy aspects of a building.

Table.1 Climatic Conditions of Different Cities in India.

\begin{tabular}{|c|c|}
\hline CITY & CLIMATE TYPE \\
\hline Ahmedabad & Hot \& Dry \\
\hline Bangalore & Temperate \\
\hline Begumpet & Composite \\
\hline Dehradun & Cold \\
\hline Guwahati & Warm \& Humid \\
\hline Surat & Hot \& Dry \\
\hline
\end{tabular}

This investigation reports on the outcomes of energy simulations with design builder software for finding the thermal comfort of naturally ventilated residential building environments by taking different window-towall ratios with an ideal window opening percentage. Moreover, it underlines the fact that along with the building envelope components building materials like wall materials, plastering materials and insulating material also plays pivotal role in influencing the thermal and energy aspects of energy efficient building. The aim of this study is primitively, to substantiate the presence of an ideal value of the ratio of the glazed surface (Sw), to the total facade surface (Sf), the nominal Window-toWall Ratio (WWR, Eq. (1))

$W W R=S w / S f$

Moreover, the determination of the intended analysis is also to inspect the abnormality, which the optimal values of window-wall-ratio might endure whether climate conditions and insulation countenance of the façade characteristics change.
Table.2 Window Dimensions as per the Window Wall Ratio

\begin{tabular}{|c|c|c|c|c|}
\hline ROOM & $\begin{array}{c}5 \% \\
\text { WWR }\end{array}$ & $\begin{array}{c}10 \% \\
\text { WWR }\end{array}$ & $\begin{array}{l}15 \% \\
\text { WWR }\end{array}$ & $\begin{array}{c}20 \% \\
\text { WWR }\end{array}$ \\
\hline HALL & $\begin{array}{c}3 ' 2 \text { "X } \\
4 \text { ' }\end{array}$ & $\begin{array}{c}4{ }^{\prime}{ }^{\prime \prime} \mathrm{X} \\
4,\end{array}$ & $\begin{array}{c}6{ }^{\prime}{ }^{\prime \prime} \mathrm{X} \\
4,\end{array}$ & $\begin{array}{c}\text { 7'8" X } \\
4,\end{array}$ \\
\hline BEDROOM & $1^{\prime} \times 4^{\prime}$ & $\begin{array}{c}2{ }^{\prime} 3 " X \\
4,\end{array}$ & $4^{\prime} \times 4^{\prime}$ & $\begin{array}{c}56^{\prime \prime} \times \\
4,\end{array}$ \\
\hline KITCHEN1 & $\begin{array}{c}\text { 1'10" X } \\
3 \text { ' }\end{array}$ & $\begin{array}{l}\text { 3'1" X } \\
\text { 3' }\end{array}$ & $\begin{array}{c}4 ' 10 " \mathrm{X} \\
3 \text { ' }\end{array}$ & $\begin{array}{c}\text { 6'4" X } \\
3,\end{array}$ \\
\hline KITCHEN2 & $1^{\prime} \times 3{ }^{\prime}$ & $\begin{array}{c}\text { 2'3" X } \\
3,\end{array}$ & $4^{\prime} \times 3{ }^{\prime}$ & $\begin{array}{c}5^{\prime} 6^{\prime \prime} \mathrm{X} \\
3,\end{array}$ \\
\hline
\end{tabular}

\section{METHODOLOGY}

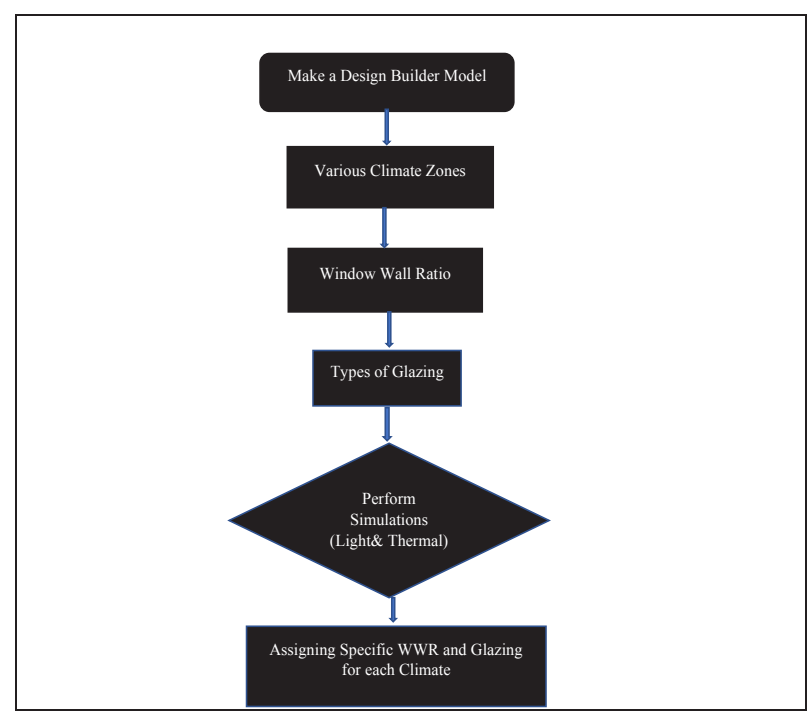

Fig.2 Methodology and procedure of the Analysis

Here, the study is proceeded in the way starting with creating a design builder model. By assuming the same model for the different cities of different climatic conditions, window-to-wall ratios of the model were determined. By considering the different type of glazing (single, double and triple glazed windows). Energy simulation (light and thermal) was carried out with the different combinations of WWR, glazing type using design builder software. From the results, we can determine the efficient WWR, glazing type and building materials.

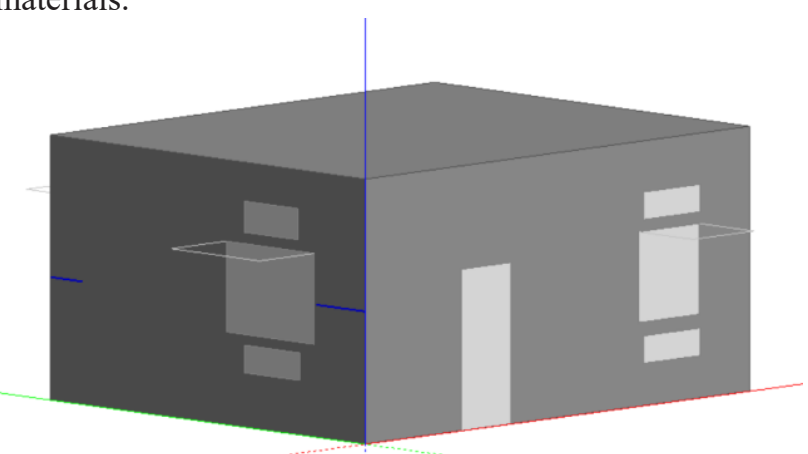

Fig. 3. Building Model in Design Builder 


\subsection{GLAZING}

Various Glazing systems are provided for the Building for the Analysing the Spatial Daylight Autonomy and the Thermal aspects for determining the total Annual Energy Consumption of the Building. There are various Glazing systems like Singe, Double and Triple Glazed Windows these Glazing system makes the alter in the Day light and the Temperature in the Building. Based on the type of Exposure the glazing system is recommended.

\subsection{SIMULATION}

The Simulations are done by using the Design builder Software for the Proposed model of the Building by altering the Window Wall Ratios and the various types of glazing for Analysing the Annual Energy Consumption and Average Temperatures of the Building.

\section{RESULTS}

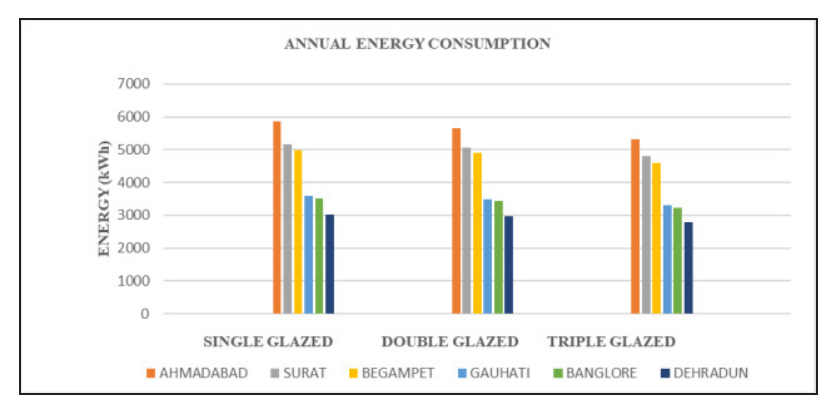

Fig. 4. Annual Energy Consumption at $15 \%$ WWR in various Glazing for the 6 Cities

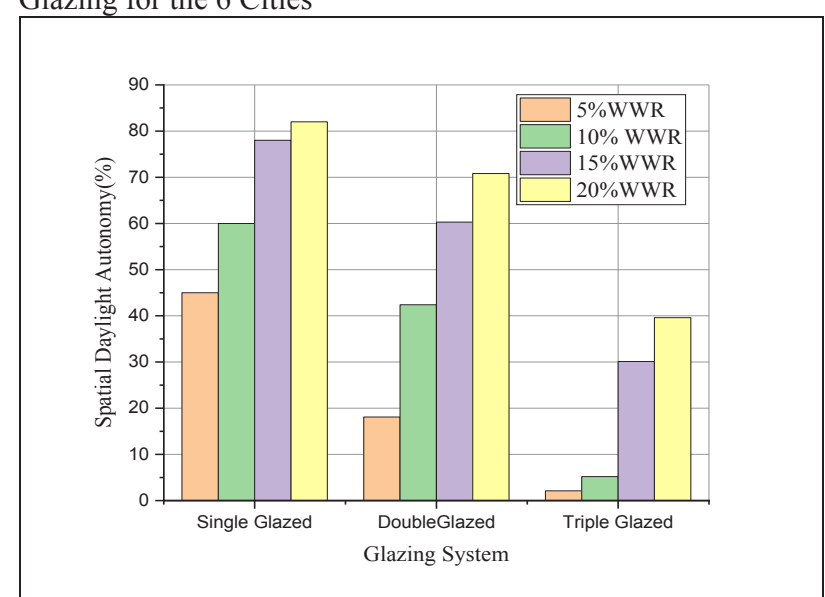

Fig. 5. Spatial Daylight Autonomy in Begumpet for various WWR and the various Glazing

The above graph defines the results of the Annual Energy Consumption of the Building for the Single, Double and Triple Glazed system for the various climatic Zones in the India at $15 \%$ of the Window Wall Ratio as the Percentage of the opening increases the amount of the light entering into the Building increases simultaneously the temperature in the Building gets Increased. The results show that the Triple Glazing system is efficient type of Glazing system in almost all the type of Climatic conditions as the Energy consumption is very low in the Cold Climatic Conditions than the Hot \& Dry Conditions. The graph shows, with the increase in the Window-Wall-Ratio there will be increase in the SDA accordingly. However, there will be also rise in the indoor temperature.

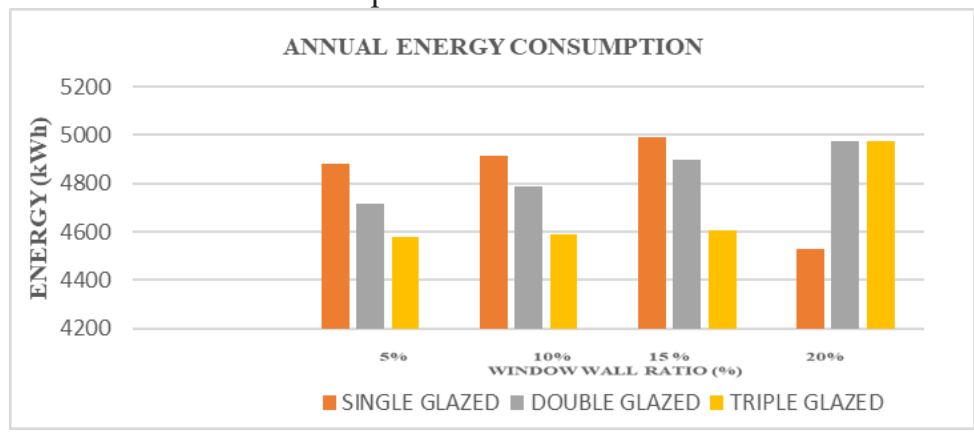

Fig. 6. Annual Energy Consumption in Begumpet for Various WWR and Glazing

The Annual Energy Consumption of the Building varies with the increase in Window Wall Ratio. As, Window Wall Ratio increases the Indoor temperature gets increases which results in the rise of the Energy Consumption. The analysis shows that the $15 \%$ of opening is optimal with the Triple Glazing.

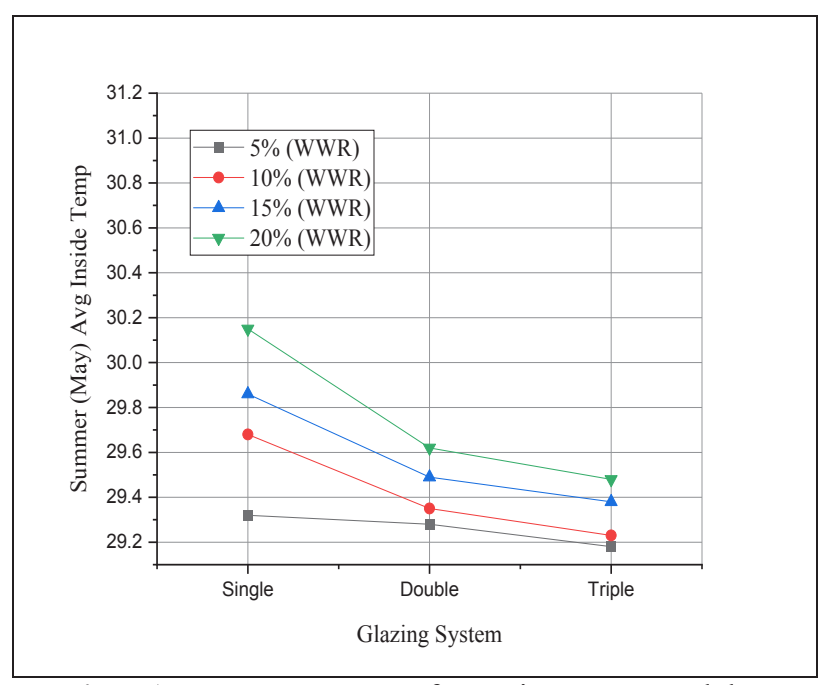

Fig. 7 Average Temperature for Various WWR and the Various Glazing

Average Temperature of the Building over the month of May is Analysed and it is found that using the Triple Glazed system is more efficient type of glazing system for maintaining the minimum temperature in the Building which ultimately reduces the Average Temperature over the period of Time. With the increase in the WWR, the indoor temperature will also get increases accordingly.

\section{CONCLUSIONS}

On this basis, the present study outlines the composition and the respective results of an investigation with a view to enhancing the Façade design of Building by varying the sizes of the pivotal parts such as Window and glazing Systems. The necessity of the investigation was to 
examine the presence of an ideal dimension of the Window surface which is the size that allows minimum overall energy Consumption.

From the analysis, Spatial Daylight Autonomy (SDA) will increase with the increase in the Window-WallRatio. Hence, we can say that SDA (Spatial Daylight Autonomy) is directly proportional to Window-WallRatio (WWR). On the other hand, single glazed system allows greater light and temperature. Looking in to the double-glazed system, it allows adequate light and temperature. whereas, triple glazed system will allow low amount of heat and light.

In terms of energy aspect, with the increase in the Window-Wall-Ratio the energy consumption will increases. Single glazing system consumes high energy compared to double and triple glazed system

The results of the considered Building model show that $10 \%$ of the Window Wall Ratio is Optimum in the aspect of the Temperature but there is reduction in the Lighting. However, $20 \%$ of the Window Wall ratio is adequate for Lighting but there is an increase in the Indoor Temperature. Hence, $15 \%$ of the Window Wall Ratio is Considered as the Optimum for both the Lighting and Temperature.

\section{Acknowledgments}

This study is supported by DST IPHEE grant from the department of science and technology (TMD/CERI/BEE/2016/096(G)). Authors acknowledge the financial support and are thankful to the department of science and technology for granting the same.

\section{REFERENCES}

1) C. Marino*, A. Nucara, M. Pietrafesa. "Does window-to-wall ratio have a significant effect on the energy consumption of buildings? A parametric analysis in Italian climate conditions", Journal of Building Engineering.

2) Xiaoling Cui, Shuaibing Yin, Lei Zhang, Yiyun Zhu*, Guochen Sang, Qin Zhao "Influence Mechanism of Window-to-Wall Ratio on Energy Consumption of Rural Buildings in Southern Shaanxi, China", International Journal of Heat and Technology Vol. 37, No. 2, June, 2019, pp. 562-568

3) Jalil Shaeri 1, Amin Habibi 1, Mahmood Yaghoubi 2 and Ata Chokhachian 3, "The Optimum Windowto-Wall Ratio in Office Buildings for Hot-Humid, Hot-Dry, and Cold Climates in Iran".

4) Moonen, P.; Defraeye, T.; Dorer, V.; Blocken, B.; Carmeliet, J. Urban Physics: Effect of the microclimate on comfort, health and energy demand. Front. Archit. Res. 2012, 1, 197-228.

5) Mamdooh alwetaishi, "impact of glazing to wall ratio in various climatic regions: A Case Study,Halil Alibaba, "Determination of Optimum Window to External Wall Ratio for Offices in a Hot and Humid Climate". 